www.jmscr.igmpublication.org

Impact Factor (SJIF): 6.379

Index Copernicus Value: 79.54

ISSN (e)-2347-176x ISSN (p) 2455-0450

crossrefDOI: https://dx.doi.org/10.18535/jmscr/v6i10.47

Journal Of Medical Science And Clinical Research

IGM Publication

An Official Publication of IGM Publication

\title{
Prevalence of Postpartum Psychiatric Disorders in a Tertiary Care Hospital in South India
}

\author{
Authors \\ Suvarna Jyothi Kantipudi ${ }^{1}$, Sathianathan Ramanathan ${ }^{2}$ \\ ${ }^{1}$ Assistant Professor, ${ }^{2}$ Professor
}

Department of Psychiatry, Sri Ramachandra Medical College \& Research Institute, Porur,

Chennai-600116, Tamilnadu, India

Corresponding Author

Dr Suvarna Jyothi Kantipudi

Assistant Professor, Department of Psychiatry, SRMC \& RI, Chennai-600116, India

Contact. No:+919047492143, Email: suvarna.srmc@ gmail.com

\begin{abstract}
Background \& Aims: The prevalence of depression during pregnancy and after childbirth is on the rise, especially in developing countries like India. Postpartum depression is a common and serious psychiatric illness, which affects approximately 19\% of women after delivery in India. It causes significant morbidity in mothers, estranges marital relationships, lowers rates of breast feeding rates and also causes poor emotional and cognitive development of the infant. Postpartum depression is generally attributed to complex interaction of genetic, hormonal and biological factors and there are very few studies which examined socio cultural factors. This study aims at identifying the prevalence of post-partum psychiatric disorders especially depression and associated socio cultural variables in a hospital based sample.

Methodology: This study is done in Sri Ramachandra medical college \& Research Institute, which is a tertiary care hospital in Chennai, Tamilnadu, India. This study employed Observational cross sectional descriptive methodology in a sample of women who were referred to psychiatrists for emotional problems in the first 6 weeks of their child's delivery. These participants were assessed using the English/Tamil translation of the Edinburgh Postnatal Depression Scale (EDPS) and also semi structured clinical interview to establish the psychiatric diagnosis using ICD-10.

Results: Out of 23 women referred to Department of Psychiatry in a period of three months for psychological problems, 8 women qualify for severe, 6 for moderate and 5 for a mild depressive episode. Two women were diagnosed to have postpartum psychosis. Majority of women referred from obstetricians had psychiatric illness. Many women reported relationship problems with in laws and dowry demand in their families. Most women said that their family had strong preference to male child.

Conclusions: Post-partum psychological problems, especially depression should be understood in the background of socio-cultural context especially in low and middle-income countries where gender inequality and poverty are prevailing. The symptoms of depression are determined by the societal expectations and cultural beliefs along with biological determinants. Understanding the personal significance of sociocultural beliefs and addressing the core schema underlying those beliefs should be considered as a part of the management. A good knowledge in obstetricians about post-partum psychiatric disorders enables regular screening and appropriate referral to psychiatrists helps in timely intervention and subsequent well-being of mother and child.
\end{abstract}

Keywords: Post-partum, Girl child, Culture, Depression, Consultation. 


\section{Introduction}

Depression is one of the leading causes of morbidity in women of child bearing age. The prevalence of depression during pregnancy and after childbirth is on the rise, especially in developing countries like India. ${ }^{1}$ Postpartum depression is a common and serious psychiatric illness, which affects approximately $19 \%$ of women after delivery in India. ${ }^{2}$ It not only causes significant morbidity in mothers, but also estranges marital relationships, lowers rates of breast feeding rates and also causes poor emotional and cognitive development of the infant. $^{3}$ Many women don't seek help for psychological problems and consider them to be part of pregnancy. However adequate knowledge about these problems in obstetricians facilitates screening and early identification and appropriate referral to mental health professionals. The postpartum psychiatric disorders include post-partum blues, post-partum depression and post-partum psychosis. Post-partum blues are usually selflimiting and don't require any intervention from professionals. Post-partum depression requires attention as it affects quality of life of the patient, family and growth of the baby, and can cause selfharm behaviour Postpartum depression is generally attributed to complex interaction of genetic, hormonal and biological factors and there are very few studies which examined socio cultural factors. The risk factors emerged through various studies in past include financial concerns, past abortions, preference for male child, spousal abuse. ${ }^{4,5}$ Some of these risk factors may be specific to certain cultures in east and may not have relevance in western population. However understanding these risk factors helps in proposing holistic management plan catering the needs of our patients. This study aims at an understanding of socio cultural risk factors and their relation to post-partum psychiatric disorders. This study is done in Sri Ramachandra medical college \& Research Institute, which is a tertiary care hospital in Chennai, Tamilnadu, India.

\section{Methodology}

This is an observational cross sectional study. The women who delivered their baby in Sri Ramachandra hospital were screened for presence of depression immediately after the birth, 2 weeks and 6 weeks after delivery using Edinburgh Postnatal Depression Scale (EDPS). It is 10 item questionnaire used commonly for screening post natal depression. Those with more than score of seven were referred to psychiatry department for further evaluation. These patients were assessed using semi structured clinical interview to establish the psychiatric diagnosis using ICD-10.Different clinical and socio cultural variables were collected using a specially designed proforma.

\section{Results}

Out of the identified 320 post-partum women in three months' time span, 23 women had EDPS score more than six and were referred to psychiatrists for further evaluation. The obstetricians refereed to psychiatrist for symptoms like emotional problems, anxiety, depression and decreased sleep. These patients were evaluated by psychiatrist in detail using structured clinical interview to establish an ICD-10 diagnosis. Of the 23 patients evaluated, 8 women qualify for severe, 6 for moderate and 5 for a mild depressive episode. Two women were diagnosed to have postpartum psychosis and two had anxiety symptoms. The prevalence of depression and psychosis during postpartum period in the hospital based sample is $5.6 \%$. and $0.6 \%$ respectively. Most of women are from rural background and are married. Majority are not working outside home and stay in a nuclear family. More than half of the women reported that they experienced demand for dowry and had financial debts. Nearly half of them reported problems in relation with in-laws. Nearly three fourths of women reported that their family had strong preference for male child. 
Table: 1

\begin{tabular}{|l|c|c|}
\hline $\begin{array}{l}\text { Socio demographic \& } \\
\text { Clinical variables }\end{array}$ & No (\%) & Mean (SD) \\
\hline Rural background & $15(64.2)$ & \\
\hline Married status & $22(97.1)$ & \\
\hline Age of mother (in years) & & $28.0(5.6)$ \\
\hline $\begin{array}{l}\text { Age of mother at first } \\
\text { pregnancy (in years) }\end{array}$ & & $25.9(4.7)$ \\
\hline Years of education & & $13.6(4.4)$ \\
\hline $\begin{array}{l}\text { Occupation -housewife/not } \\
\text { employed outside home }\end{array}$ & $14(60.8)$ & \\
\hline Unemployment in spouse & $5(21.7)$ & \\
\hline Nuclear family & $17(73.9)$ & \\
\hline Regular alcohol use in spouse & $11(47.8)$ & \\
\hline Marital discord present & $6(26.1)$ & \\
\hline Demand for dowry & $13(56.5)$ & \\
\hline Poor relationship with in-laws & $11(47.8)$ & \\
\hline Having debt & $14(60.9)$ & \\
\hline $\begin{array}{l}\text { Family history of psychiatric } \\
\text { illness }\end{array}$ & $4(17.4)$ & \\
\hline $\begin{array}{l}\text { Past history of psychiatric } \\
\text { illness }\end{array}$ & $3(13.0)$ & \\
\hline Unplanned pregnancy & $4(17.4)$ & \\
\hline $\begin{array}{l}\text { In-laws/spousal preference } \\
\text { for male child }\end{array}$ & $17(73.9)$ & \\
\hline $\begin{array}{l}\text { Caeserian delivery for current } \\
\text { childbirth }\end{array}$ & $17(73.9)$ & \\
\hline $\begin{array}{l}\text { No.of women with ICD-10 } \\
\text { criteria for severe depression }\end{array}$ & $6(26.1)$ & \\
\hline Total EDPS score & & \\
\hline
\end{tabular}

Table: 2

\begin{tabular}{|l|c|}
\hline Diagnosis & No. of Patients \\
\hline Postpartum depression & 19 \\
\hline Postpartum psychosis & 2 \\
\hline Anxiety NOS & 2 \\
\hline
\end{tabular}

\section{Discussion}

The risk of women having post-partum disorders is high. Along with biological vulnerability, lot of social and cultural contribute to depression. Inspite of progress in the society, certain social and cultural beliefs strongly influence our thoughts, emotions and behaviour. Dowry both giving and taking is a punishable offense, but still continues in our society. The preference for male child is do strong in our community and can contribute to self-blame, guilt and negative reactions towards female child. Although the lot of women are educated very few are working outside home as child bringing is a responsibility of women alone in most families. Despite equal opportunities of education and economic independence in current world, woman continues to remain as a victim of domestic injustice and their services remain unrecognized. We explored the possible reasons for such attitude towards female by looking into literature. Women enjoyed equal status with women during Early Vedic period. However during Later Vedic period their status deteriorated. The strong preference for male child roots back to later Vedic period, where birth of a son was welcomed due to belief that a son would save his father from the hell called "Punnama narakam". ${ }^{6}$ Manusmriti a book on social philosophy, mentions that "Day and night woman must be kept in dependence by the males of their families Her father protects her in childhood, her husband protects her in youth and her son protects her in old age". ${ }^{7}$ Legally, woman was given equal right with man; but practices like dowry continue to prevail in Indian sub-continent. These beliefs along with socially disadvantageous position of women concern many mothers to welcome a girl child. Blame from spouse and in laws and concerns regarding safety and future of girl child are associated with maternal depression.

\section{Conclusions}

Post-partum psychological problems, especially depression should be understood in the background of socio-cultural context especially in low and middle-income countries where gender inequality and poverty are prevailing. Girl child is still considered as liability in our society. The symptoms of depression are determined by the societal expectations and cultural beliefs along with biological determinants. Understanding the personal significance of socio-cultural beliefs and addressing the core schema underlying those beliefs should be considered as a part of the management. A good consultation model is very essential for early identification and effective treatment of post-partum psychiatric illness.

\section{Source of Support: Nil}

Conflict of Interest: None 


\section{References}

1. Global variation in the prevalence and incidence of major depressive disorder: a systematic review of the epidemiological literature. - PubMed - NCBI [Internet]. [cited 2018 Sep 21]. Available from: https://www.ncbi.nlm.nih.gov/pubmed/2283 1756

2. Upadhyay RP, Chowdhury R, Aslyeh Salehi, Sarkar K, Singh SK, Sinha B, et al. Postpartum depression in India: a systematic review and meta-analysis. Bull World Health Organ. 2017 Oct 1;95(10):706-717C.

3. Patel V, DeSouza N, Rodrigues M. Postnatal depression and infant growth and development in low income countries: a cohort study from Goa, India. Arch Dis Child. 2003 Jan;88(1):34-7.

4. Chandran M, Tharyan P, Muliyil J, Abraham S. Post-partum depression in a cohort of women from a rural area of Tamil Nadu, India. Incidence and risk factors. $\mathrm{Br} \mathrm{J}$ Psychiatry J Ment Sci. 2002 Dec;181:499504.

5. Savarimuthu RJS, Ezhilarasu P, Charles H, Antonisamy B, Kurian S, Jacob KS. Postpartum depression in the community: a qualitative study from rural South India. Int J Soc Psychiatry. 2010 Jan;56(1):94-102.

6. Atharva Veda: Book 20: Book 20 index [Internet]. [cited 2018 Sep 21]. Available from: https://www.sacredtexts.com/hin/av/avbook20.htm

7. The Laws of Manu IX [Internet]. [cited 2018 Sep 21]. Available from: https://www.sacredtexts.com/hin/manu/manu09.htm 